\title{
Tobacco Use and Related Risk Factors, Surveillance
}

National Cancer Institute

\section{Source}

National Cancer Institute. Tobacco Use and Related Risk Factors, Surveillance. NCI

Thesaurus. Code C15987.

Research studies that assess trends in tobacco-related risk factors, behaviors and health services to determine changes over time and the influence of these trends on cancer incidence, morbidity, mortality and survival. (NCI/T RIP) 